УДК 628.234

\title{
П.Н. ГУБАНОВ
}

доктор технических наук, заведующий кафедрой экологии и природопользования

Нижегородский государственный архитектурно-строительный университет

\section{A.Ю. 3BEPEBA}

ассистент кафедры экологии и природоподьзования

Нижегородский государственный архитектурно-строительный университет

\section{В.И. ЗВЕРЕВА}

кандидат химических наук, профессор кафедры экологии и природопользования

Нижегородский государственный архитектурно-строительный университет

\section{ВАИЯНИЕ ПОЯИГОННОГО ДЕПОНИРОВАНИЯ ТВЕРДЫХ БЫТОВЫХ ОТХОДОВ НА СОСТОЯНИЕ ПОДЗЕМНЫХ И ПОВЕРХНОСТНЫХ ВОД}

\author{
INFLUENCE OF LANDFILL DEPOSITION OF MUNICIPAL SOLID WASTE ON GROUND AND SURFACE WATERS
}

Больиинство полигонов не удовлетворяет требованиям, предъявляемым к условиям складирования отходов, и представляют собою свалки, на которых отсутствует инженерная инфраструктура, обеспечивающая защиту объектов биосферы от загрязнений. Химические и микробиологические процессы, протекающие в твердой массе бытового мусора, приводят к образованию вредных веществ, загрязняющичх водные объекты.

В проектах полигонов ТБО должна быть двухстадийная схема очистки стоков. Первая стадия очистки осуществляется в прудах-регуляторах большой емкости за счет усреднения, разбавления и длительного отстаивания стоков. Вторая - обеспечивается на сооружениях физико-химической и биологической очистки. Негативное влияние остаточных вредных веществ на состояние подземных вод уменьшается, если между экраном и ближайшим к нему водоноснылм горизонтом, существует достаточно мощный естественный геохимический барьер, т.е. наличие в основании полигона пород, способных эффективно препятствовать выносу загрязнений в горизонты подземных вод.

Ключевъе слова: полигоны, ТБО, биосфера, экранирование, химические и микробиологические процессы, подземные воды, окружающяая среда.

Подигоны твердых бытовых отходов концентрируют на ограниченной территории значительное количество вредных веществ, которые создаются в результате протекания многообразных химических, ферментативных и биохимических реакций. В результате этих процессов образуются биогаз, фильтрат, твердая масса, а также выделяется тепло. Фильтрат является основным поставщиком токсичных веществ в поверхностные и подземные воды. Вредные вещества, содержащиеся в выделяющемся с полигона биогазе, загрязняют атмосферный воздух, а образующаяся твердая масса формирует тех-
Most landfills don't meet the requirements for the terms of waste disposal and are just dumps without any engineering infrastructure protecting biosphere objects from polluting. Chemical and microbiological processes occurring in the municipal solid waste mass lead to the formation of harmful substances polluting water objects.

The designs of landfills MSW should have a two-stage scheme of wastewater treatment. The first stage of treatment is done in ponds-regulators of high capacity by homogenisation, dilution and long-lasting settling of wastewater. The second stage of treatment is performed on plants of physical-chemical and biological treatment. Negative influence of the rest harmful substances decreases if there is a big enough natural biochemical barrier between the water wall and the nearest water-bearing level, i.e. if the basement of the landfill has rocks that can effectively prevent pollutants' taking out to ground water levels.

Key words: landfills, MSW, biosphere, water walling, chemical and microbiological processes, ground waters, environment.

ногенные свалочные грунты. Следует отметить, что наибольшее негативное влияние полигоны, предназначенные для размещения ТБО, оказывают на поверхностные и подземные воды [1-3].

В России большинство подигонов не удовлетворяют требованиям, предъявдяемым к условиям складирования отходов, и представляют свалки, на которых отсутствует инженерная инфраструктура, обеспечивающая защиту объектов биосферы от загрязнений. На протяжении всего жизненного цикла полигон захоронения ТБО явдяется источником экологической опасности для окружающей среды [4]. 
Воздействие полигона на объекты гидросферы обусловлено образующимися при деструкции ТБО фильтрационными водами, которые формируются в результате инфильтрации атмосферных осадков, отжимных вод, биохимических и химических процессов разложения отходов.

Наиболее значимыми факторами, оказывающими влияние на содержание и объем фильтрационных вод, являются морфологический состав ТБО, мощность полигона, влажность отходов, кдиматические условия, инженерная инфраструктура поиигона, предварительная обработка отходов ${ }^{1,2}$.

Химические и микробиологические процессы, протекающие в твердой массе бытового мусора, приводят к образованию вредных веществ, загрязняющих водные объекты. Просачивающиеся воды в свалках отходов образуются при воздействии на компоненты отходов грунтовых вод и атмосферных осадков. Состав этих вод в основном зависит от вида хранящихся отходов. Если в хранилищах промышленных отходов просачивающиеся воды содержат в себе те же вещества, что и сами отходы, то со свалок бытового мусора вымываются продукты брожения и гниения органических веществ.

Особенно опасны просачивающиеся воды старых хранилищ и свалок, в которых не проводилось характерного для настоящего времени разделения (сортировки) бытовых и промышленных отходов. В массе таких отходов может происходить взаимодействие между веществами, образовавшимися при анаэробном брожении, и токсичными веществами промышленных отходов, что приводит к образованию еще более вредных веществ.

Одним из главных путей распространения загрязнений с территории складирования отходов явдяются поверхностные воды, стекающие с территории во время сильных дождей, и особенно фильтрат - жидкая фаза, выделяющаяся из отходов при прохождении через их тодщу атмосферных осадков. Состав и концентрация неорганических и органических загрязнений вод зависят от состава отходов, способа эксплуатации подигона, места складирования, интенсивности и характера процесса раздожения органических соедине-

${ }^{1}$ Российская Федерация. Законы. Об охране окружающей среды. От 10.01.2002 № 7 - ФЗ [Электронный ресурс]: [ред. от 22.08.2004 № 122 - ФЗ]. Режим доступа: Консультант Плюс. Законодательство.

${ }^{2}$ Российская Федерация. Законы. Об отходах производства и потребления. От 24.08.1998 № 89 - Ф3 [Электронный ресурс]: [ред. от 05.03.2005 № 17 - Ф3]. Режим доступа: Консультант Плюс. Законодательство. ний, проницаемости слоя, а также от совокупности климатических условий. Основными параметрами, влияющими на состав и количество фильтрата, явАяются:

а) компонентный состав и степень раздожения ТБО;

б) размер и технические характеристики попигона;

в) характеристики верхнего покрывающего слоя;

г) объем и состав дождевых и талых вод.

Фильтрат образуется в результате протекания процессов деподимеризации, сбраживания, гумификации органического вещества, сульфатредукции и других процессов. В результате образуются токсичные сточные воды с высоким содержанием макро- и микрокомпонентов. Особенно опасны соединения тяжелых металлов (цинка, свинца, никеля, хрома, кадмия и др.). Основными органическими соединениями в фильтрате явдяются ароматические углеводороды, ациклические карбонильные соединения, карбоновые кислоты и т.д. Наиболее опасны загрязнения органического происхождения, оцениваемые химической потребностью в кислороде (ХПК).

Поскольку твердые бытовые отходы представляют собой сложную гетерогенную систему, состоящую из многих компонентов, то необходимо предвидеть возможность протекания как гетерогенных реакций на границе раздела фаз, так и гомогенных реакций в объеме жидкой, твердой и газообразной фаз. Состав веществ, входящих в отходы, чрезвычайно разнообразен. Из органических соединений - это жиры, белки, эфиры, полисахариды, высокомолекулярные природные подимеры и т.д. Из неорганических компонентов в состав отходов входят оксиды, соли, кислоты, гидроксиды, комплексные и хелатные соединения. Между этими разнообразными веществами может протекать множество химических, ферментативных и биохимических реакций. Присутствие кислорода и воды приводит к еще большему разнообразию процессов. В связи с этим можно описать только общие механизмы взаимодействия органических и неорганических веществ, приводящие в дальнейшем к образованию токсичных веществ, загрязняющих наземные и подземные воды.

К общим механизмам раздожения сложных молекул органических веществ следует отнести ступенчатые процессы, в результате которых происходит отрыв концевых групп. Одновременно происходит активизация карбоксильных, 
гидроксильных, амидных и других функциональных групп, входящих в состав исходных и вновь образованных молекул.

Аэробные химические процессы протекают при доступе атмосферного воздуха и хорошей аэрации, т.е. при достаточном количестве кислорода и при хорошем отводе образующихся веществ. Химическому превращению в аэробных условиях подвергаются термодинамически неустойчивые соединения, окислению и гидролизу - молекулы клетчатки, сахаров, витаминов, крахмала, мочевины, дипидов, аминокислот и многих других соединений. При этом образуются простейшие кислоты, альдегиды, кетоны, спирты и другие соединения, растворяющиеся в воде. В продуктах гидродиза сложных эфиров могут присутствовать меркаптоспирты, замедляющие аэробные процессы в твердой массе твердых бытовых отходов.

Анаэробные процессы протекают под вдия-

нием микроорганизмов анаэробов и сопровождаются выделением метана, аммиака, сероводорода и простейших спиртов. Многие из этих соединений хорошо растворимы в воде. Состав загрязнителей в фильтрате зависит от фазы брожения органических соединений и существенно - от времени нахождения отходов на полигоне.

Фильтрат, вытекающий из тела свалки, условно можно классифицировать на «мододой», характерный для начадьной (кислотной) стадии, и «старый», образующийся в период стабилизации процессов биодеструкции отходов. Состав загрязнений в просачивающихся водах определяется фазой брожения веществ, содержащихся в ТБО, и существенно зависит от времени их хранения на полигонах и свалках. Типовой химический состав фильтрата, полученный по результатам исследований многогих свалок США и стран Западной Европы, приведен в табл. 1.

Таблица 1

Типовой химический состав фидьтрата

\begin{tabular}{|c|c||c|c|}
\hline Химический элемент & Содержание, мг/л & Химический элемент & Содержание, мг/л \\
\hline Железо & $(200 \div 1700)$ & Сера & $(25 \div 500)$ \\
\hline Цинк & $(1 \div 135)$ & Хлор & $(100 \div 2400)$ \\
\hline Свинец & $(5 \div 130)$ & Натрий & $(100 \div 3800)$ \\
\hline Азот & $(20 \div 500)$ & & \\
\hline
\end{tabular}

В табл. 2 приведена концентрация загрязнителей в фильтрате полигонов ТБО.

Таблица 2

Концентрации загрязнителей в фильтрате полигонов

\begin{tabular}{|c|c|c|c|c|c|}
\hline $\begin{array}{c}\text { Наименование ком- } \\
\text { понентов или показа- } \\
\text { тели состава и свойств } \\
\text { воды } \\
\end{array}$ & $\begin{array}{c}\text { ПДК рыб.- } \\
\text { хоз., мг/А }\end{array}$ & $\begin{array}{c}\text { Содержание } \\
\text { в фильтрате, } \\
\text { мг/л }\left(\mathrm{M}_{\mathrm{i}}\right)\end{array}$ & $\begin{array}{c}\text { Наименование ком- } \\
\text { понентов или показа- } \\
\text { тели состава и свойств } \\
\text { воды }\end{array}$ & $\begin{array}{c}\text { ПДК рыб.- } \\
\text { хоз., мг/л }\end{array}$ & $\begin{array}{c}\text { Содержание } \\
\text { в фильтрате, } \\
\text { мг/л }\left(\mathrm{M}_{\mathrm{i}}\right)\end{array}$ \\
\hline БПК (полное) & 5 & 1500 & Никель & 0,01 & 0,82 \\
\hline ХПК & 30 & 4200 & Марганец & 0,01 & 0,22 \\
\hline ПАВ: сульфоно & 0,1 & 4,7 & Дитий & 0,0007 & 0,65 \\
\hline неионогенные & 0,1 & 90 & Кобальт & 0,01 & 0,8 \\
\hline Сульфаты & 100 & 44 & Молибден & 0,0012 & 0,2 \\
\hline Хиориды & 300 & 3500 & Нефтепродукты & 0,05 & 12 \\
\hline Нитраты & 40 & 30 & Этилбензол & 0,001 & 0,4 \\
\hline Аммоний & 0,5 & 2400 & Ксило $\lambda$ & 0,05 & 0,4 \\
\hline Натрий & 120 & 2750 & Фено 1 & 0,001 & 0,29 \\
\hline Железо & 0,1 & 122 & Хиорбензо & 0,001 & 0,1 \\
\hline Кремний & 10 & 6,8 & 1,2-дихлорбензо & 0,002 & 0,1 \\
\hline Свинец & 0,1 & 0,32 & Фуриловый спирт & 0,5 & 4 \\
\hline Сурьма & 0,05 & 1,47 & Анилин & 0,0001 & 0,2 \\
\hline Кадмий & 0,005 & 0,023 & Триэтиламин & 1 & 25 \\
\hline Медь & 0,001 & 0,35 & Высшие жиры & 0,1 & 1,48 \\
\hline Цинк & 0,01 & 2,45 & & & \\
\hline
\end{tabular}


В фильтратах, просачивающихся со свалок городского мусора, содержатся соединения щелочных и щелочно-земельных металлов, тяжелых металлов, а также различные органические вещества, в частности фенолы, кислоты, альдегиды, нефтепродукты, спирты и др. Просачивающиеся со свалок воды должны улавдиваться дренажной системой и отводиться в очистные сооружения.

С целью уменьшения загрязнения наземных и подземных вод вредными веществами при эксплуатации полигона должен быть предусмотрен комплекс мер, препятствующих проникновению загрязняющих компонентов в водные объекты. Экологическим мониторингом предусматривается контродь качества поверхностных и подземных вод в зоне потенциального влияния полигона. По результатам гидрогеологических исследований устанавливаются уровни и направления потоков подземных вод, а также располагаются пункты наблюдательной сети скважин и гидропостов на водостоках. Режимная сеть скважин проектируется обычно по лучевой системе от центра участка захоронения отходов и включает в себя:

- фоновый, гидрогеологический створ, установленный вверх по потоку подземных вод;

- два-три гидрогеологических створа, установленных по наиболее вероятным направлениям распространения загрязнений от полигона по горизонтам подземных вод. Среднее расстояние между скважинами составдяет 300-500 м.

Закладка режимной наблюдательной сети производится до строительства основных объектов полигона. В течение года снимаются фоновые показатели режима и химического состава подземных вод в районе полигона.

Проектирование полигонов ТБО ведется на основе концепции минимизации экологического риска, согласно которой необходимо максимально снижать экологическую нагрузку на окружающую среду,и в частности на водные объекты. Дия этого необходимо:

- при выборе площадки под ТБО учитывать весь комплекс физико-географических условий;

- учитывать климатические условия района;

- выполнять мероприятия по минимизации выноса загрязняющих веществ в водные объекты;

- предусмотреть комплекс сооружений по сбору загрязненных стоков со всей территории полигона, их очистке и отведению;

- обеспечить изоляцию слоев укладываемых отходов и устройство внешнего водозащитного покрытия полигона с рекультивацией его поверхности;

- осуществлять эффективную дегазацию массива отходов на всех этапах существования подигона;

- предусмотреть проведение мониторинга за состоянием окружающей среды.

По топографическим условиям наиболее благоприятны участки с умеренно-наклонным рельефом, желательно односклоновые, примыкающие одной стороной к динии поверхностного водораздела, что значительно упрощает отвод фильтрата.

По гидрологическим параметрам благоприятными условиями явдяются минимадьная площадь водосбора, максимадьная водность приемника стоков полигона и отсутствие водозаборов.

По геологическому строению благоприятным является залегание с поверхности слоя четвертичных отложений мощностью 4 м и более.

По гидрогеологическим условиям наиболее приемлемы те варианты размещения площадки, по которым:

- слой глинистых грунтов в основании (ниже дна котлована) более 2 м;

- уровень первого от поверхности горизонта подземных вод залегает ниже подошвы гдинистого слоя;

- вся площадка располагается по одну сторону от подземного водораздела;

- поток основного горизонта подземных вод направлен к водотоку с менее жесткими экологическими требованиями;

- вниз по водотоку отсутствуют водозаборы подземных и поверхностных вод.

Защита водных объектов в зоне потенциального влияния ТБО осуществляется с помощью грунтово-пленочного экрана, основным водоупорным элементом которого является подиэтиленовая пленка. Для сохранения изолирующих свойств экрана при случайных повреждениях пленки используется слой гдинистого грунта толщиной не менее $1 \mathrm{~m}$.

Эффективность экранирования оценивается отношением объема предотвращенной при помощи экрана фильтрации к тому ее объему, который существовал бы в случае отсутствия экрана. Эффективность экранирования достигает 70 \% при толщине пленки 0,2 мм и 90 \% при пленке толщиной 1 мм.

Негативное вдияние остаточной фильтрации на состояние подземных вод снижается, если 
между экраном и ближайшим к нему водоносным горизонтом существует достаточно мощный естественный геохимический барьер, в частности наличие в основании полигона глинистых пород, способных эффективно препятствовать выносу загрязнений полигона в горизонты подземных вод. Такой барьер одновременно выполняет функции естественного противофильтрационного экрана, уменьшающего общий объем загрязненных стоков и природного сорбционного и ионообменного фильтра, задерживающего значительную часть загрязнений из фильтрующихся через него стоков. Для максимального использования защитного эффекта геохимического барьера предпочтение отдается площадкам с глубоким залеганием подземных вод.

В проектах полигонов ТБО предусматривается двухстадийная схема очистки стоков. Первая стадия очистки осуществляется в прудах-регуляторах большой емкости за счет усреднения, разбавления и длительного отстаивания стоков. Вторая стадия очистки обеспечивается на сооружениях физикохимической и биологической очистки.

Сооружения второй ступени могут работать только после предварительной первичной очистки, где происходит уменьшение БПК фильтрата от 1500 до 200-300 мг/ л, допустимой для биологической очистки стоков. При емкости пруда-регулятора, равной примерно сренегодовому объему стоков, расчетная степень очистки по БПК составдяет более 80 \%, и величина БПК стоков на выходе из пруда не будут превышать допустимых значений для последующей биологической очистки. Поэтому пруд-регулятор достаточно бодьшой емкости является основным звеном системы очистных сооружений полигона.

Защита водных объектов от загрязнения вредными веществами обычно решается при помощи противофильтрационной защиты, т.е. специальных экранов. Данная защита предусматривает:

-минимизацию объемов образования фильтрата полигона за счет поэтапного освоения территории и устройства водозащитного покрытия по внешним откосам и поверхности массива отходов;

- уменьшение объемов фильтрационных утечек через основание полигона за счет устройства искусственного барьера (противофильтрационного экрана) и дренажной системы, обеспечивающих отвод фильтрата с полигона;
- уменьшение сброса загрязняющих веществ в водные объекты путем фильтрации через искусственный барьер за счет максимального использования естественного (природного) геохимического барьера.

Искусственный барьер проектируется в виде грунтово-пленочного экрана, основным водоупорным элементом которого является пленка из подимерного материала. Следует отметить, что абсолютно непроницаемых экранов не существует. Их эффективность оценивается на уровне 70 \% для относительно тонких подимерных пленок, до 90 \% - для толстых пленок.

Негативное влияние остаточных вредных веществ на состояние подземных вод в значительной мере уменьшается, если между экраном и ближайшим к нему водоносным горизонтом, существует достаточно мощный естественный геохимический барьер, под которым понимается наличие в основании полигона таких пород (главным образом гдинистых), которые способны эффективно препятствовать выносу загрязнений подигона в горизонты подземных вод.

В настоящее время хранилища, а также свалки для бытового мусора следует эксплуатировать как промежуточные места складирования ТБО, чтобы избежать их длительного воздействия на окружающую среду.

\section{БИБЯИОГРАФИЧЕСКИЙ СПИСОК}

1. Дюбешкина, Е. Г. Твердые бытовые отходы. Проблемы и решения [Текст] / Е. Г. Любешкина // Экспресс-информ./ВИНИТИ.Сер. Ресурсосберегающие технологии».- 2002. - № 24. - С. 3-7.

2. Журкович, В. В. Отходы: науч. и учеб.-метод. справ. пособие [Текст] / В. В. Журкович, А. И. Потапов. СПб. : Гуманистика, 2001. - 580 с.

3. Ибатуллин, У.Г. Переработка отходов перспективный компонент рынка экологических услуг [Текст] / У.Г. Ибатуллин, С.М. Ибатулдина // Экономика природоподьзования : обзор. информ. / ВИНИТИ. - 2001. № 1. - C. 60-63.

4. Концепция обращения с твердыми бытовыми отходами в Российской Федерации [Текст]: МДС 13-8.2000. - M., 2000. - 17 c.

С Губанов Л.Н., Зверева А.Ю., Зверева В.И., 2011 